\title{
Physical Activity in Normal-Weight and Overweight Youth: Associations with Weight Teasing and Self-Efficacy
}

\author{
Stefanie Losekam ${ }^{\mathrm{a}}$ Benjamin Goetzky ${ }^{\mathrm{a}}$ Svenja Kraeling ${ }^{\mathrm{a}}$ Winfried Rief $^{\mathrm{b}} \quad$ Anja Hilbert $^{\mathrm{b}}$ \\ ${ }^{\text {a }}$ Christoph Dornier Foundation of Clinical Psychology, \\ ${ }^{\mathrm{b}}$ Department for Psychology, Philipps University of Marburg, Marburg, Germany
}

\section{Keywords}

Weight teasing - Physical activity - Self-efficacy .

School children $\cdot$ Social context

\section{Summary}

Objective: To examine self-reported physical activity with regard to weight teasing and self-efficacy. Methods: Within a cross-sectional study, 321 overweight and normal-weight students, consisting of $51 \%$ girls ( $n=161$ ) and $49 \%$ boys $(n=160)$ at a mean age of 12.22 years (SD = 1.07), were sampled from German secondary schools. The Perception of Teasing Scale, the Physical Self-Efficacy Scale, and the Leipzig Lifestyle Questionnaire for Adolescents were used to assess experiences with weight-related teasing, self-efficacy, physical activity and social context variables. Results: Self-efficacy, weight teasing and social context variables were related to physical activity within the full sample $\left(R^{2}=0.433\right)$. More frequent weight teasing was associated with decreased physical activity in boys, but not in girls. Overweight participants reported more frequent weight teasing experiences and less self-efficacy than participants of normal weight (all $p<0.001$ ), but there was no difference in physical activity $(p>0.05)$. There were large correlations between self-efficacy and physical activity ( $r=0.614, p<0.01)$, and medium correlations for male sex and physical activity $(r=0.298, p<0.01)$. Weight teasing and self-efficacy were negatively correlated $(r=-0.190, p<0.05)$. Conclusions: These results suggest that self-efficacy and an encouraging social context are beneficial to physical activity while weight teasing experiences are detrimental. Interventions against weight teasing in youth are needed.

\section{Introduction}

Experiences of weight stigmatization, for example being teased about their weight, are widespread among children, especially among overweight youth. Weight teasing has been found to have harmful effects on health-related variables in youth [1]. However, little is known about the implications of weight-related teasing on physical activity in children and adolescents. Previous research on physical activity in youth predominantly documented the importance of self-efficacy [2]. Nevertheless, further exploration on correlates of self-efficacy with regard to physical activity in boys and girls is currently warranted.

Weight teasing seems to be detrimental to physical activity in youth. Among those children who had been teased about their body weight, some reported a negative attitude towards physical exercise and, hence, had reduced their physical activity levels [3-5]. Research suggests that weight teasing is associated with sex and weight status. Girls and heavier children have been found to be exposed to more weight-related teasing than boys and normal-weight children [3]. Overweight children were more likely to be excluded from games and physical activities, and reported feeling embarrassed participating in any kind of physical activity because of their weight $[5,6]$. Moreover, a decrease in physical activity and an increase of sedentary behaviors were found to be associated with higher body fat in youth [7]. In summary, while there is some indication that weight teasing has an effect on physical activity in youth, further explorations with regard to weight status and sex are called for.

In youth, self-efficacy has been found to be strongly associated with physical activity [2]. Self-efficacy is a concept that was derived from Bandura's social-cognitive theory [8] and

\section{KARGER}

Fax +497614520714

Information@Karger.de

www.karger.com (c) 2010 S. Karger GmbH, Freiburg

Accessible online at:

www.karger.com/ofa 
refers to people's belief in their capability to achieve a desired effect. In adolescents, the relationship between female sex, higher weight status and lower self-efficacy has frequently been documented $[9,10]$. Recently, there is increasing evidence for the significance of social context variables, i.e. family and peer groups, on self-efficacy $[2,11,12]$ and physical activity in youth [13-19]. According to sports sciences, girls were found to be less physically active than boys [20-25]. Nevertheless, across different age groups, girls especially were found to gain from parental and friends' support with regard to their self-efficacy beliefs and physical activity levels [26, 27]. However, this has been studied only sparsely. Thus, further research on the social context in relation to self-efficacy and physical activity and with regard to sex and body weight is necessary.

The present study aims to investigate physical activity with regard to weight-related teasing and self-efficacy in normalweight and overweight youth. First, it is hypothesized that a higher weight status, greater weight teasing, less self-efficacy and less physical activity are significantly associated. Second, overweight participants are expected to experience more frequent weight teasing and to report less self-efficacy and less physical activity than normal-weight participants. Third, a better integration into peer networks and parents who exercise often are assumed to be related to higher levels of selfefficacy. Fourth, less self-efficacy and more frequent weight teasing are assumed to be related to lower levels of physical activity. Since both the experiences of frequent weight-related teasing [1] and encouragement of physical activity by family and peers $[26,27]$ have been found to be associated with sex, the third and fourth hypothesis will be tested on boys and girls separately.

\section{Material and Methods}

\section{Sample}

School-based data were collected in September 2008. In line with age groups investigated in recent studies, students - grade 5 through 8 - from three German secondary schools (Gesamtschulen) were sampled and answered a 1-hour set of questionnaires (see measures) during school hours. Each student was offered movie vouchers by way of compensation. All participants and parents had read and signed an informed consent form prior to the investigation. The Hessian Ministry of Education and School Agency granted ethical approval for the conduct of this study.

A total of 367 participants were selected for the current study. Out of these 367,46 were excluded on grounds of incomplete measures, leaving a final sample of $\mathrm{N}=321$, consisting of $51 \%$ girls $(\mathrm{n}=161)$ and $49 \%$ boys $(\mathrm{n}=160)$ with a mean age of 12.22 years $(\mathrm{SD}=1.07$ years $)$, a mean BMI of $18.75 \mathrm{~kg} / \mathrm{m}^{2}\left(\mathrm{SD}=3.07 \mathrm{~kg} / \mathrm{m}^{2}\right)$, and a mean BMI percentile of 43.32 ( $\mathrm{SD}=28.90)$. BMI was calculated from self-reported weight and height measurements. Correlations between measured and reported weight usually exceed 0.80 and 0.90 in youth [28]. According to German guidelines [29], children with a BMI greater than the 90th percentile based on age and sex were classified as overweight or obese ( $>97$ th BMI percentile). In the current study, $9 \%(\mathrm{n}=28)$ were classified as being overweight, including 4 obese participants. This number is lower than national epi- demiologic findings suggest. In comparison, the percentage of overweight in children and adolescents in Germany is about 15\% [30]. A migratory background was reported by $8 \%$ of the participants $(\mathrm{n}=25)$, which is also lower than reported by literature. In $2005,28.5 \%$ children and adolescents from 0 to 18 years were found to have a migratory background in Germany [31]. Overweight and obese participants did not differ from normal-weight participants in age, sex or ethnicity (all p >0.05).

\section{Measures}

\section{Weight Teasing}

The well-established Perception of Teasing Scale (POTS) [32] assesses the frequency and stress of weight-related teasing (e.g. 'People made fun of you because you were heavy'). The POTS consists of six items answered on a five-point scale ranging from $1=$ 'never' to $5=$ 'frequently'. There are acceptable results for validity and reliability for the original POTS version [32]. In this study we used a German version of the POTS (Hilbert et al., unpublished) with appropriate statistical properties (Goetzky et al., in preparation).

\section{Self-Efficacy}

The Physical Self-Efficacy Scale [33] was selected to measure children's like (or dislike) of physical activity and beliefs about their physical abilities, using seven items (e.g. 'I am good at sports compared to peers'). Items were rated on a five-point scale ranging from 1 = 'I don't agree' to $5=$ 'I entirely agree'. Acceptable results for reliability, validity as well as norms have been reported [33].

\section{Physical Activity and Social Network Variables}

The Leipzig Lifestyle Questionnaire for Adolescents [34] is a standardized self-report instrument that is currently used to examine the impact of different lifestyles on weight status in youth [35, 36]. Test statistic properties such as construct validity, retest reliability and norms, based on a representative sample of 1,001 German students, have been reported [34]. It consists of six youth lifestyle scales and six parental lifestyle scales, all rated utilizing the adolescents' self-report questionnaires. All items are rated on a five-point scale ranging from $1=$ 'never' to $5=$ 'most frequently'. The nine-item subscale 'physical activity' that assesses average frequencies of various leisure-time physical activities (e.g. 'How often do you play soccer?') was used to measure physical activity in youth. The subscale 'groups' consists of five items and assesses the amount of integration into peer networks in youth (e.g. 'Do you often spend time with friends?'). In addition, the two-items subscale 'parental exercise level' was used to measure the frequency of parental leisure-time activities from their children's perspective (e.g. 'Do your parents exercise regularly and often?').

\section{Data Analysis}

Analyses were conducted with SPSS for Windows 11.5 (Chicago, IL, USA). First, we tested associations between weight teasing, physical activity and self-efficacy by computing zero-order correlations using Pearson correlations. Sizes of correlation effects were interpreted according to Cohen [37], defining $r \geq 0.10$ as small, $r \geq 0.30$ as medium and $r \geq 0.50$ as large effects. Second, independent $t$ tests were conducted in order to compare means of overweight and normal-weight participants. Third, in order to examine associations with self-efficacy, hierarchical regression analyses were computed for the full sample, and for boys and girls separately. Predictor variables were entered stepwise, and all independent variables with significant $\mathrm{F}$ test results were included into the model. Demographic variables, including sex, age, BMI percentile and ethnicity, were entered in the first block. Peer network was entered in the second and parental exercise level in the third block. Finally, to examine associations with physical activity, stepwise hierarchical regression analyses were applied as de- 
scribed above. Demographic variables were entered in the first block, self-efficacy in the second block, weight teasing in the third block and peer network and parental exercise level were entered in the last block. Effect size of prediction was evaluated according to Cohen [37] with $\mathrm{R}^{2}$ $\geq 0.019$ indicating a small, $R^{2} \geq 0.13$ indicating a medium and $R^{2} \geq 0.51$ indicating a large effect. A two-tailed alpha level of 0.05 was used for all statistical tests.

\section{Results}

\section{Associations between Weight, Weight Teasing, Self-Efficacy and Physical Activity}

As presented in table 1, there were large positive zero-order correlations between self-efficacy and physical activity as well as medium correlations between higher BMI percentiles and more weight-related teasing. More weight teasing was asso- ciated with lower self-efficacy. There was no association between physical activity and BMI percentile, or physical activity and weight teasing.

\section{Group Differences between Overweight and Normal Weight Participants}

As presented in table 2, there was greater weight-related teasing and less self-efficacy in overweight than in normal-weight participants, but there were no differences in the reported physical activity.

\section{Hierarchical Stepwise Regression Analysis on Self-Efficacy}

In both boys and girls the prediction on self-efficacy by peer network and parental exercise level revealed a medium effect size (table 3). Greater BMI percentiles were found to be associated with lower self-efficacy in boys, but not in girls.
Table 1. Correlations between physical activity, weight teasing, and self-efficacy

Table 2. Group differences in physical activity, weight teasing, and self-efficacy

\begin{tabular}{llccc}
\hline & Sex $($ male $)$ & BMI percentile & Weight teasing & Self-efficacy \\
\hline Sex $($ male $)$ & - & & & \\
BMI percentile & $0.124^{*}$ & & & \\
Weight teasing & 0.026 & $0.424^{* *}$ & & \\
Self-efficacy & $0.169^{* *}$ & $-0.140^{* *}$ & $-0.190^{* *}$ & $0.614^{* *}$ \\
Physical activity & $0.298^{* *}$ & 0.013 & 0.024 & \\
\hline * $<0.05, * * \mathrm{p}<0.01$. & & & & \\
\hline
\end{tabular}

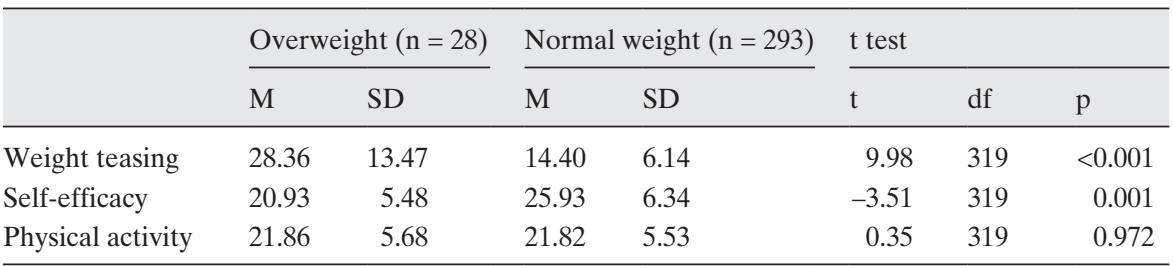

$\mathrm{M}=$ means, $\mathrm{SD}=$ standard deviations, $\mathrm{t}=\mathrm{t}$ coefficient, $\mathrm{df}=$ degrees of freedom, $\mathrm{p}=$ alpha level.

Table 3. Hierarchical stepwise regression analysis on self-efficacy

\begin{tabular}{|c|c|c|c|c|c|c|}
\hline \multirow[t]{2}{*}{ Blocks of variables } & \multicolumn{2}{|l|}{ Full sample $(\mathrm{n}=321)$} & \multicolumn{2}{|l|}{ Boys $(n=160)$} & \multicolumn{2}{|l|}{ Girls $(\mathrm{n}=161)$} \\
\hline & Variable & $\beta$ & Variable & $\beta$ & Variable & $\beta$ \\
\hline Demographic variables & $\begin{array}{l}\mathrm{R}^{2}=0.055 \\
\operatorname{sex}(\text { male })\end{array}$ & $0.189 * *$ & $\mathrm{R}^{2}=0.053$ & & $\mathrm{R}^{2}=0.030$ & \\
\hline & BMI percentile & $-0.163 * *$ & BMI percentile & -0.230 ** & & 0 175** \\
\hline Peer network & $\begin{array}{l}\Delta \mathrm{R}^{2}=0.132 * * \\
\text { peer network }\end{array}$ & $0.365^{* *}$ & $\begin{array}{l}\Delta \mathrm{R}^{2}=0.191^{* *} \\
\text { peer network }\end{array}$ & $0.439 * *$ & $\begin{array}{l}\Delta \mathrm{R}^{2}=0.129^{* *} \\
\text { peer network }\end{array}$ & $0.379 * *$ \\
\hline Parental exercise level & $\begin{array}{l}\Delta \mathrm{R}^{2}=0.035^{*} \\
\text { parental exercise level }\end{array}$ & $0.193 * *$ & & & $\begin{array}{l}\Delta \mathrm{R}^{2}=0.086^{* *} \\
\text { parental exercise level }\end{array}$ & $0.300 * *$ \\
\hline Total $\mathrm{R}^{2}$ & 0.433 & & 0.244 & & 0.246 & \\
\hline
\end{tabular}

$\beta=$ standardized regression coefficient.

$* \mathrm{p}<0.05, * * \mathrm{p}<0.01$. 
Table 4. Hierarchical stepwise regression analysis on physical activity

\begin{tabular}{|c|c|c|c|c|c|c|}
\hline \multirow[t]{2}{*}{ Blocks of variables } & \multicolumn{2}{|l|}{ Full sample $(\mathrm{n}=321)$} & \multicolumn{2}{|l|}{ Boys $(n=160)$} & \multicolumn{2}{|l|}{ Girls $(\mathrm{n}=161)$} \\
\hline & Variable & $\beta$ & Variable & $\beta$ & Variable & $\beta$ \\
\hline \multirow[t]{2}{*}{ Demographic variables } & $\mathrm{R}^{2}=0.089$ & & & & & \\
\hline & sex (male) & $0.298 * *$ & & & & \\
\hline \multirow[t]{2}{*}{ Self-efficacy } & $\Delta \mathrm{R}^{2}=0.327 * *$ & & $\mathrm{R}^{2}=0.349$ & & $\mathrm{R}^{2}=0.372$ & \\
\hline & self-efficacy & $0.581 * *$ & self-efficacy & $0.591 * *$ & self-efficacy & $0.610 * *$ \\
\hline \multirow[t]{2}{*}{ Weight teasing } & $\Delta \mathrm{R}^{2}=0.017 * *$ & & $\Delta \mathrm{R}^{2}=0.040 * *$ & & & \\
\hline & weight teasing & $-0.135 * *$ & weight teasing & $-0.204 * *$ & & \\
\hline \multirow[t]{3}{*}{ Social context } & $\Delta \mathrm{R}^{2}=0.047 * *$ & & $\Delta \mathrm{R}^{2}=0.054 * *$ & & $\Delta \mathrm{R}^{2}=0.040 * *$ & \\
\hline & peer network & $0.165 * *$ & peer network & $0.148 * *$ & peer network & $0.273 * *$ \\
\hline & parental exercise level & $0.143 * *$ & parental exercise level & $0.172 * *$ & & \\
\hline Total $\mathrm{R}^{2}$ & 0.481 & & 0.443 & & 0.412 & \\
\hline
\end{tabular}

Hierarchical Stepwise Regression Analysis on Physical

Activity

Self-efficacy, peer network and parental exercise level were related to physical activity with medium effect sizes in both boys and girls (table 4). Increased weight teasing was associated with decreased physical activity in boys, but not in girls.

\section{Discussion}

Concerns about physical inactivity, particularly among overweight youth, have become current public health issues [38] The present study sought to examine associations between weight-related teasing, self-efficacy and physical activity in normal-weight and overweight youth. The results provide support for harmful weight teasing effects on physical activity. Furthermore, encouragement to being more physically active by social context and self-efficacy were associated with higher levels of physical activity.

Results provide evidence for greater vulnerability to weight-related teasing in overweight than in normal-weight children and adolescents, which is in line with previous findings $[1,4]$. Regression analyses within the present study show that weight teasing was associated with lower physical activity in both normal-weight and overweight youth. While the literature predominantly documented lower physical activity levels based on weight teasing in overweight youth [3, 5, 39], there have also been findings to demonstrate higher preferences for sedentary activities based on weight teasing in 10- to 14-year-olds regardless of weight status [4], which is supported by the present study. Surprisingly, there were no differences in self-reported physical activity in overweight and normal-weight participants. Presumably, this can be explained by response biases which are likely inherent to self-reported physical activity $[24,40]$. In future investigations, it would be desirable to complement self-report measures of physical activity with objective measures, for example, accelerometry. Regarding sex differences, the present study found the male sex to be related to greater levels of physical activity, which is consistent with previous findings [20-25], indicating that attempts to reduce obstacles to physical activity should target girls in particular. With regard to the examination of experiences and impact of weight-related teasing for boys and girls separately, the present results provide some new information: While boys reported lower physical activity levels associated with weight teasing, girls did not, although weight teasing has been found to be associated with lower physical activity in girls earlier [3]. One explanation of this result might be that, among girls, weight-related teasing more likely affects other variables than physical activity, for example, eating habits [41, 42]. Furthermore, it is also possible, that girls consider different variables as an obstacle to physical activity than boys do [24]. Overweight girls reported receiving less adult encouragement for physical activity than normal-weight girls, whereas there was no difference in boys. In addition, the present findings confirmed the importance of the social context for higher self-efficacy and physical activity, which is in line with previous findings [2,11,13-15], particularly in girls [26, 27]. Hence, it is necessary to include the social context to increase selfefficacy and physical activity, especially in girls, as recommended by other authors earlier [43-47].

The results of this study should be viewed within the context of its strengths and limitations. First, the investigation of both sexes is certainly among the strengths of the study. All previous studies only asked for the investigation of weightrelated teasing and self-efficacy in association with sex and body weight $[1,26,27]$. Within the present study, separate regression analyses revealed sex differences regarding asso- 
ciations with physical activity. Second, a large range of body weight types was covered, making it possible to compare overweight and normal-weight participants. Third, data was collected using validated measures with appropriate statistical values, which makes the current results comparable to other investigations examining weight teasing, physical activity, selfefficacy and peer and family support in youth. In the future, self-report measures of parental physical activity and social integration should be complemented, for example, by parent questionnaires. In addition, it would be desirable to assess the pubertal status in order to interpret age or sex effects. The main limitations of the present study are surely based on its cross-sectional design. It provides evidence for group differences and associations between variables. But to evaluate causal mechanisms underlying the present results, long-term studies would be necessary. Furthermore, cross-sectional data are vulnerable to memory biases. For example, overweight participants were found to report more experiences of weightrelated teasing because they might remember more teasing situations, or they might use being teased as an excuse for their sedentary activity choices. Nevertheless, the present study confirmed harmful teasing effects on physical activity in line with the literature. Therefore, the risk of memory bias is assumed to be acceptable. Another limitation is the fact that BMI was assessed through self-report only. Even though studies have shown that self-reported heights and body mass values were fairly accurate by comparison with objective measures $[28,48]$, recent literature indicated biases in self-reported BMI in youth [49]. Thus, it cannot be excluded that some overweight participants did not report their real body weight and therefore were assigned to the normal-weight sample and limited the reliability of classification.
This study provides clinical implications for the prevention of childhood overweight and other health risks associated with physical inactivity. Based on the present results, interventions to prevent experiences of weight-related teasing or to limit the effects thereof are needed [50]. In Germany, so far, in spite of multiple approaches to prevent overweight in youth [51], no attempts specifically addressing weight-related teasing have been made. To our knowledge, only few studies have attempted to reduce weight teasing in youth, such as the V.I.K. program (Very Important Kids) [52]. According to the V.I.K. program, interventions against negative effects of weight teasing targeting family and school staff include i) the reduction of negative comments on children's body weight, ii) the establishment of activities to impact children's level of body satisfaction at individual and environmental levels, iii) the education about the impact of media influences, iv) the establishment of healthy eating habits and $v$ ) the increase of physical activity [52]. According to evidence-based recommendations to increase physical activity in youth, it will be important to incorporate physical activity into daily family routines [53], to accompany children whenever they engage in physical activity [15], to inform parents and peers on their role model influences [12] and to reinforce children, especially girls, whenever they are physically active [15]. Future research should target further approaches to tackle the consequences of the stigma of overweight [50,54], weight-related teasing in particular, and to effectively increase physical activity in youth [55].

\section{Disclosure}

The authors declared no conflict of interest.

\section{References}

1 Puhl RM, Latner JD: Stigma, obesity, and the health of the nation's children. Psychol Bull 2007; 133:557-580.

2 Sallis JF, Prochaska JJ, Taylor WC, Hill JO, Geraci JC: Correlates of physical activity in a national sample of girls and boys in grades 4 through 12 . Health Psychol 1999;18:410-415.

$\checkmark 3$ Faith MS, Leone MA, Ayers TS, Heo M, Pietrobelli A: Weight criticism during physical activity, coping skills, and reported physical activity in children. Pediatrics 2002;110:e23.

4 Hayden-Wade HA, Stein RI, Ghaderi A, Saelens BE, Zabinski MF, Wilfley DE: Prevalence, characteristics, and correlates of teasing experiences among overweight children vs. non-overweight peers. Obes Res 2005;13:1381-1392.

5 Bauer KW, Yang YW, Austin SB: 'How can we stay healthy when you're throwing all of this in front of us?' Findings from focus groups and interviews in middle schools on environmental influences on nutrition and physical activity. Health Educ Behav 2004;31:34-46.

6 Pierce JW, Wardle: Cause and effect beliefs and self-esteem of overweight children. J Child Psychol Psychiatr 1997;38:645-650.
7 Marshall SJ, Biddle SJ, Gorely T, Cameron N, Murdey I: Relationships between media use, body fatness and physical activity in children and youth: a meta-analysis. Int J Obes 2004;28:1238-1246.

8 Bandura, A: Social Foundations of Thought and Action: A Social Cognitive Theory. Englewood Cliffs, Prentice Hall, 1986.

9 Deforche BI, De Bourdehaudhuij IM, Tanghe AP: Attitude toward physical activity in normal-weight, overweight and obese adolescents. J Adolesc Health 2006;38:560-568.

10 Craig S, Goldberg J, Dietz W: Psychological correlates of physical activity among fifth and eighth graders. Prev Med 1996;25:506-513.

11 De Bourdeaudhuij I, Lefervre J, Deforche B, Wihndaele K, Matton L, Philippaerts R: Physical activity and psychosocial correlates in normal weight and overweight 11 to 19 year olds. Obes Res 2005;13:1097-1105.

12 Anderson CB, Hughes SO, Fuemmeler BF: Parentchild attitude congruence on type and intensity of physical activity: testing multiple mediators of sedentary behavior in older children. Health Psychol 2009;28:428-438.
13 Lown D, Braunschweig CL: Determinants of physical activity in low-income, overweight African American girls. Am J Health Behav 2008;32:253-259.

14 Page RM, Ihasz F, Simonek J, Klarova R, Hantiu J: Friendships and physical activity: Inverstigating the connection on Central-Eastern European adolescents. Int J Adolesc Med Health 2007;19:187-198.

15 Duncan SC, Duncan TE, Strycker LA: Soucres and types of social support on youth physical activity. Health Psychol 2005;24:3-10.

16 Bös K, Opper E, Woll A, Liebisch R, Breithecker D, Kremer B: Fitness in der Grundschule. Haltung und Bewegung 2001;21:4-67.

17 Dordel S: Bewegungsförderung in der Schule. 4. Aufl. Dortmund, Verlag modernes lernen, 2003.

18 Wahler P, Tully CJ, Preiss C: Jugendliche in neuen Lernwelten. Selbstorganisierte Bildung jenseits institutioneller Qualifizierung. Wiesbaden, VS Verlag, 2008.

19 Graf C, Koch B, Kretschmann-Kandel E, Falkowski G, Christ H, Coburger S, Lehmacher W, Bjarnason-Wehrens B, Platen P, Tokarski W, Predel HG, Dordel S: Correlation between BMI, leisure habits and motor abilities in childhood (CHILT-Project). Int J Obes 2004;28:22-26. 
20 Kleine W: Tausend gelebte Kinder. WeinheimMünchen, Juventa Verlag, 2003.

21 Bundesministerium für Familie, Senioren, Frauen und Jugend: Gender-Datenreport, 2005. www. bmfsfj.de/Publikationen/genderreport/root.html.

-22 Buksch J, Finne E: Messung der motivationalen Bereitschaft zu körperlicher Aktivität. Präv Gesundheitsf 2008;3:179-186.

23 Lampert T, Mensinck GBM, Romahn N, Wol A: Körperlich-sportliche Aktivität von Kindern und Jugendlichen in Deutschland. Ergebnisse des Kinder- und Jugendgesundheitssurveys (KiGGS). Bundesgesundheitsbl Gesundheitsforsch Gesundheitsschutz 2007;50:634-642.

24 Zabinski MF, Saelens BE, Stein RI, Hayden-Wade HA, Wilfley DE: Overweight children's barriers to and support for physical activity. Obes Res 2003; 11:238-246.

25 Allison KR, Dwyer JJM, Makin S: Perceived barriers to physical activity among high school students. Prev Med 1999;28:608-615.

26 Motl RW, Dishman RK, Saunders RP, Dowda M, Pate RR: Perceptions of physical and social environment variables and self-efficacy as correlates of self-reported physical activity among adolescent girls. J Pediatr Psychol 2007;32:6-12.

27 Gruber K: Social support for exercise and dietary habits among college students. Adolescence 2008, 43:557-575.

28 Shannon B, Smiciklas-Wright H, Wang MQ: Inaccuracies in self-reported weights and heights in a sample of sixth-grade children. J Am Diet Assoc 1991;91:675-678.

29 Kromeyer-Hauschild K, Wabitsch M, Kunze D, Geller F, Geiss HC, Hesse V, von Hippel A, Jaeger U, Johnson D, Korte W, Menner K, Mueller G, Mueller JM, Niemann-Pilatus A, Remer T, Schaefer F, Wittchen HU, Zabransky S, Zellner K, Ziegler A, Hebebrand J: Perzentile für den BodyMass-Index für das Kindes- und Jugendalter unter Heranziehung verschiedener deutscher Stichproben. Monatsschr Kinderheilkd 2001;149:807-818.

-30 Kurt BM, Schaffrath Rosario A: Die Verbreitung von Übergewicht und Adipositas bei Kindern und Jugendlichen in Deutschland. Ergebnisse des bundesweiten Kinder- und Jugendgesundheitssurveys (KiGGS). Bundesgesundheitsbl Gesundheitsforsch Gesundheitsschutz 2007;50:736-743

31 Statistisches Bundesamt, Mikrozensus: Bevölkerung nach Migrationserfahrung und Alter, 2005.
32 Thompson JK, Cattarin J, Fowler B, Fisher E: The perception of teasing scale (POTS): a revision and extension of the physical appearance related teasing scale (PARTS). J Pers Assess 1995;65:146-157.

33 Roth M: Das Körperbild im Jugendalter. Diagnostische, klinische und entwicklungspsychologische Perspektiven. Aachen, Verlag Mainz, 1998.

34 Beckert-Zieglschmid C, Brähler E: Der Leipziger Lebensstilfragebogen für Jugendliche (LlfJ). Göttingen, Vandenhoeck \& Rupprecht, 2007.

35 Beckert-Zieglschmid C, Riepl W, Kiess W, von Klitzing K, Braehler E: Ernährung und Lebensstil bei Übergewicht und Adipositas. Ergebnisse einer repräsentativen Befragung junger Erwachsener. Adipositas 2008;2:133-141.

36 Gerhards J, Roessel J: Lebensstile und ihr Einfluss auf das Ernährungsverhalten von Jugendlichen. Soziale Welt 2002;53:261-284.

37 Cohen L: Statistical Power Analysis for the Behavioral Science. Hillsdale, Lawrence Erlbaum Associates, 1998.

38 Bundesministerium für Ernährung, Landwirtschaft und Verbraucherschutz, Bundesministerium für Gesundheit: IN FORM. Deutschlands Initiative für gesunde Ernährung und mehr Bewegung. Berlin, Eurodruck, 2008.

39 Storch EA, Milsom VA, DeBraganza N, Lewin AB, Geffken GR, Silverstein JH: Peer victimization, psychosocial adjustment, and physical activity in overweight and at-risk-for-overweight youth. J Ped Psychol 2007;32:89-89.

40 Janssen I, Katzmarzyk PT, Boyce WF, Vereecken C, Mulvihill C, Roberts C, Currie C, Pickett W; Health Behaviour in School-Aged Children Obesity Working Group: Comparison of overweight and obesity prevalence in school-aged youth from 34 countries and their relationships with physical activity and dietary patterns. Obes Rev 2005;6:123-132.

41 Neumark-Sztainer D, Falkner N, Story M, Perry C, Hannan PJ, Mulert S: Weight-teasing among adolescents: correlations with weight status and disordered eating behaviors. Int J Obes 2002;26:123-131.

42 Neumark-Sztainer D, Wall MM, Haines JI, Story MT, Sherwood NE, van den Berg PA: Shared risk and protective factors for overweight and disordered eating in adolescents. Am J Prev Med 2007; 33:359-369.

43 Graf C, Dordel S, Koch B, Predel HG: Bewegungsmangel und Übergewicht bei Kindern und Jugendlichen. Dtsch Z Sportmed 2006;57:220-225.
44 Graf C, Koch B, Jaeschke R, Dordel S: Die Kinder-Bewegungspyramide. Bonn, Academia-Verlag, 2005.

45 International Obesity Task Force: The obesity epidemic, metabolic syndrome and future prevention strategies. Eur J Cardiovasc Prev Rehabil 2004;11 3-8.

46 Kavey REW, Daniels SR, Lauer RM, Atkins DL, Hayman LL, Taubert K: American Heart Association Guidelines for primary prevention of atherosclerotic cardiovascular disease beginning in childhood. Circulation 2003;107:1562-1566.

47 Committee on Sports Medicine and Fitness and Committee on School Health: Physical fitness and activity in schools. Pediatrics 2000;105:1156-1157.

48 Strauss RS: Comparison of measured and self-reported weight and height in a cross-sectional sample of young adolescents. Int J Obes Relat Metab Disord 1999:23:904-908.

49 Kurth BM, Ellert U: Gefühltes oder tatsächliches Übergewicht: Worunter leiden Jugendliche mehr? Dtsch Arztebl 2008;105:406-412.

50 Schmalz DL: 'I feel fat': weight-related stigma, body esteem, and BMI as predictors of perceived competence in physical activity. Obes Facts 2010;3: 15-21.

51 Pigeot I, Bosche H, Pohlabeln H: Programme der Primärprävention von Adipositas und Übergewicht im Kindes- und Jugendalter. Bundesgesundheitsbl Gesundheitsforsch Gesundheitsschutz 2004;47:256-265.

52 Haines J, Neumark-Sztainer D, Perry CL, Hannan PJ, Levine MP: V.I.K. (Very Important Kids): a school-based program designed to reduce teasing and unhealthy weight-control behaviors. Health Educ Res 2006;21:884-895.

53 Anderson AS, Wojcik JR, Winett RA, Williams DM: Social-cognitive determinants of physical activity: the influence of social support, self-efficacy, outcome expectations, and self-regulation among participants in a church-based health promotion study. Health Psychol 2006;25:510-520.

54 Hilbert A: The burden of the burden: current advances in weight stigma research. Obes Facts 2010; 3:5-6.

55 Talema R: Tracking of physical activity from childhood to adulthood: a review. Obes Facts 2009;2: 187-195. 